\title{
A imigração polonesa para São Paulo no pós-Segunda Guerra Mundial no quadro das entradas dos "deslocados de guerra": 1947 a $1951^{\star}$
}

\author{
Sênia Bastos ${ }^{\star \star}$ \\ Maria do Rosário Rolfsen Salles ${ }^{* * *}$
}

O presente trabalho se insere no âmbito da história social da imigração para São Paulo, focalizando especificamente o período comumente classificado como a retomada da imigração, no pós-Segunda Guerra Mundial, quando as entradas se dividem basicamente em dois momentos: 1947-1951, com o apoio da Organização Internacional das Migrações (OIR); e 1952-1980, com o apoio do Comitê Intergovernamental para as Migrações Europeias (Cime). 0 estudo enfoca a nacionalidade polonesa no quadro da imigração dos chamados "deslocados de guerra”, provenientes dos campos de refugiados da Alemanha e da Áustria. Com base na documentação do Memorial do Imigrante, sistematizada em um banco de dados, e nos artigos publicados na Revista de Imigração e Colonização (RIC), procura-se contextualizar a discussão do período, sobre a necessidade e conveniência ou não da entrada desses imigrantes deslocados que foram introduzidos graças a acordos entre o Brasil e a OIR, além de traçar o perfil desses imigrantes, que formavam o maior grupo entre as nacionalidades entradas no período. O foco na imigração polonesa do pós-guerra ressalta a especificidade desse fluxo, cujo perfil se diferencia das levas anteriores num contexto marcado, preferencialmente, pela proteção ao trabalhador nacional e ao migrante interno.

Palavras-chave: Imigração. Pós-Segunda Guerra. Deslocados. Poloneses. São Paulo.

\footnotetext{
*A pesquisa integra o projeto temático Fapesp, processo 2009/06502-2.

** Universidade Anhembi Morumbi, São Paulo-SP, Brasil (bseniab@terra.com.br).

*** Universidade Anhembi Morumbi, São Paulo-SP, Brasil (mrrsalles@anhembimorumbi.edu.br).
} 


\section{Introdução}

As origens da imigração em massa no Brasil, assim como na Argentina, EUA e Canadá, remontam a meados do século XIX, como é bastante conhecido, em virtude da crise geral provocada pela instabilidade política e econômica resultado tanto das guerras napoleônicas como da industrialização nos países europeus, sobretudo aqueles de unificação tardia como a Itália e a Alemanha. No caso brasileiro, as primeiras levas até finais do século constituíramse, em sua maioria, por imigrantes provenientes da Espanha, Portugal e norte da Itália.

No contexto das migrações internacionais, os estudos têm ressaltado suficientemente que o Brasil, país de imigração, que tradicionalmente recebeu imigrantes de diferentes nacionalidades, sobretudo no período da "grande imigração", entre as décadas finais do século XIX e as primeiras do século XX, apresenta, a partir dos anos 1980, tendência à emigração. Dada a importância dos fluxos para a agricultura cafeeira, muitas pesquisas foram produzidas no sentido de ressaltar a transição do trabalho escravo para o trabalho livre (FAUSTO, 1991), fazendo com que o tema da imigração propriamente dita ficasse, de certa forma, secundário em relação ao problema maior da transição e que os estudos se centrassem na imigração rural. A experiência urbana da imigração e os fluxos do pós-Segunda Guerra Mundial revestem-se, desta forma, da maior importância para a história da imigração no Brasil e o real dimensionamento do seu peso no contexto geral da industrialização.

Assim, o objetivo do presente artigo é traçar um perfil dos imigrantes de nacionalidade polonesa em São Paulo no contexto mais geral da imigração do pós-Segunda Guerra Mundial, em que os poloneses entraram juntamente com as demais nacionalidades dos chamados “deslocados de guerra”, no período 1947-51, quando as entradas, em sua maioria, foram patrocinadas pela Organização Internacional dos Refugiados. Assim, na retomada da imigração pelo Brasil, em 1945, a legislação imigratória, apesar da preferência por imigrantes de origem latina como portugueses, espanhóis e italianos, discutiu e aprovou a entrada daqueles provenientes dos campos de refugiados da Alemanha e da Áustria, em parte por razões humanitárias que eram propaladas, mas sobretudo pelo caráter técnico e especializado desses imigrantes que possuíam qualificação muitas vezes obtida nos próprios campos.

\section{As fases da imigração brasileira: da imigração de massa ao pós-guerra}

Costuma-se datar a retomada da imigração pelo governo brasileiro em 18 de setembro de 1945, quando, ainda dentro do Estado Novo, foi sancionado o Decreto-Lei n. 7.967, segundo o qual o Brasil reabre a imigração, embora mantendo o sistema de cotas que havia imprimido o caráter restritivo à imigração que caracterizou a era Vargas desde 1934. Tal sistema restritivo estabelecia que, de cada nacionalidade, só podia imigrar anualmente para o país 2\% do total que havia entrado entre 1884 e 1934, de acordo com o artigo 121 da Constituição de 1934 (KOIFMAN, 2012).

Baseando-se em artigo de Levy (1974), que reúne as estatísticas disponíveis para a análise dos diferentes períodos que compõem o processo imigratório brasileiro, Bassanezi (1995) 
assinala quatro momentos, mais longos e de maior intensidade, de entradas de imigrantes, separados por períodos mais curtos de declínio abrupto. No primeiro, caracterizado pela política de imigração subsidiada e pela direção do fluxo às lavouras cafeeiras do oeste do Estado de São Paulo, ocorreu a entrada maciça de imigrantes, em sua maioria italianos, constituindo o "período áureo" da imigração italiana, de 1886 até 1902, quando então a Itália proibiu, pelo Decreto Prinetti (1902), a imigração subsidiada para o Brasil, momento que coincidiu com a crise da economia cafeeira que se desencadeou no final do século XIX (CENNI, 2002; TRENTO, 1989). O segundo iniciou-se com a política de valorização do café e com a assinatura do Convênio de Taubaté em 1906 e se encerrou às vésperas da Primeira Guerra Mundial. Neste período ocorreu o crescimento das imigrações portuguesa e espanhola e o começo da japonesa. O terceiro, iniciado no final da Primeira Guerra Mundial e que vai até o fim do Estado Novo e da Segunda Guerra Mundial, caracteriza-se por um aumento no volume da imigração portuguesa e das entradas daqueles imigrantes classificados como “outras nacionalidades" (poloneses, russos, romenos, judeus, etc.), além de japoneses. É o período em que se encerrou a política de imigração subsidiada, apresentou-se novamente uma crise de superprodução cafeeira, que teve seu ponto culminante em 1929-30, e iniciouse a política de restrições à imigração.

O quarto período, iniciado portanto no pós-Segunda Guerra Mundial, se caracteriza por um afrouxamento das restrições anteriores, apresentando um volume de entradas bem inferior ao anterior e no qual se inserem os "deslocados de guerra”. ${ }^{1}$ Os maiores números de entradas, a partir de 1950, corresponderam aos portugueses, seguidos pelos italianos, espanhóis e finalmente pelos chamados “outras nacionalidades", rubrica sob a qual costumam aparecer as nacionalidades que compõem os “deslocados”. Os japoneses também registraram números bastante expressivos a partir dos anos 1950.

Nesse período a cafeicultura deixou de ser o polo mais dinâmico da economia e de atração de imigrantes, para ceder lugar à indústria e à colonização agrícola. Passaram a vigorar basicamente a imigração espontânea, que se dava por meio das “cartas de chamada” de parentes e oferta de empregos, a qual se caracterizava por grupos e cooperativas com vistas, sobretudo, à colonização agrícola, e a imigração dirigida, orientada pelos convênios entre o governo brasileiro e organismos internacionais. A partir dos anos 1960, declinou novamente o movimento imigratório, que se limitou a técnicos e profissionais, instituindo-se o ingresso dos coreanos² e, a partir da década de 1980, ocorreram um fluxo significativo de latino-americanos e um movimento no sentido contrário, de emigração de brasileiros para países desenvolvidos como Japão, países da Europa e EUA (BAENINGER, 2012).

\footnotetext{
${ }^{1}$ Segundo Lobo (1950), o conceito de "deslocado" difere do de "refugiado", uma vez que refugiado é o indivíduo que sai mais ou menos espontaneamente do seu país de origem, por razões políticas ou religiosas, enquanto o "deslocado" (o Displaced person - Dp), definido após a Guerra, foi retirado à força de seu país e levado para a Alemanha sob regime de trabalho forçado.

2 Entre os países americanos que mais receberam imigrantes coreanos o Brasil está em terceiro lugar, precedido pelos Estados Unidos e Canadá (MONTEIRO; BASTOS, 2011).
} 
Os mais importantes acordos que o Brasil assinou no pós-Segunda Guerra Mundial foram com países afetados pela guerra, como Itália, Espanha, além do Japão e da Holanda. Quanto aos deslocados e refugiados, foram criados organismos internacionais, como a United Nations Relief and Rehabilitation Administration (UNRRA), agência criada sob os auspícios dos Estados Unidos e que foi substituída pela Organização Internacional dos Refugiados (OIR), em 1947, que tinham como objetivos o repatriamento e a colocação das populações deslocadas pela guerra. O Brasil, assim como o Estado de São Paulo, assinou acordos para entrada de imigrantes “deslocados de guerra”, que se encontravam em campos de refugiados na Alemanha e na Áustria. Em matéria de imigração, a novidade é realmente a criação dos organismos internacionais, que passaram a se encarregar da repatriação ou colocação dos imigrantes europeus em outros países da Europa, na Austrália, no Canadá, nos EUA e em países latino-americanos, cada um dos quais passando a determinar as regras e condições para a entrada de imigrantes.

Como chama a atenção Lobo (1950), a partir da Primeira Guerra Mundial, foram introduzidas profundas transformações na estrutura política, econômica e social de todo o mundo, particularmente nos países envolvidos na emigração/imigração, de modo a criar exigências e condições muito diferentes daquelas do período anterior, que se caracterizava pelo regime liberal do laissez faire. Segundo o autor, as migrações não mais poderiam se ajustar aos antigos métodos e às organizações já obsoletas, por se basearem na ação unilateral de indivíduos ou de nações interessadas. Impunham-se, então, a coordenação e a cooperação no campo internacional.

\section{Os “deslocados de guerra" e o debate sobre sua entrada}

O Brasil foi um dos primeiros países a se interessar pela seleção desse tipo de imigrantes, bem como um dos primeiros signatários do Acordo proposto pela ONU para colocação desses imigrantes (ANDRADE, 2005), o que, segundo Lobo (1950), denota não o propalado desejo de ajudar a resolver um problema humanitário, mas sim o interesse pela mão de obra qualificada dessas pessoas. Os chamados “deslocados de guerra” são caracterizados pela saída forçada de seus países e pelo trabalho forçado nos campos de concentração durante a guerra. Eles possuíam treinamento técnico e qualificação profissional e se caracterizavam por apresentar um número grande de jovens treinados e com capacitação para o trabalho industrial.

A Revista de Imigração e Colonização (R/C), publicação do Departamento de Imigração e Colonização, mostra em artigos publicados desde o período anterior ao final da guerra posições bastante díspares com relação à entrada dos chamados "deslocados": alguns ressaltavam as qualidades desses imigrantes como técnicos e qualificados, enquanto outros destacam os perigos de se receber uma população não latina e traumatizada pela guerra. Não se deixava de valorizar aqueles imigrantes considerados mais adequados ao país, ou seja, italianos, portugueses e espanhóis, pela sua origem latina e religião, línguas e culturas mais 
próximas, argumento que sempre pautou a política imigratória brasileira que valorizava o branqueamento da população e a mais fácil assimilação. A R/C reproduzia artigos publicados pela grande imprensa, a legislação em vigor, relatórios, dados, estudos e pareceres, que eram consultados por técnicos e autoridades diplomáticas, "em busca de uma orientação para a questão imigratória brasileira” (PERES, 1994, p. 54).

Ao se aproximar o final da guerra, sobretudo o término da década de 1940, os artigos refletem não apenas discussões sobre a necessidade da imigração e da seleção, mas também as medidas concretas que foram aparecendo no sentido da introdução de novos imigrantes. O bom imigrante continuava sendo o agricultor, mas aparecia claramente a necessidade do novo, do técnico, do indivíduo qualificado para o trabalho industrial. Assim, os artigos do período de 1947 a 1950 da R/C aliam imigração e desenvolvimento, rumo ao Brasil do futuro, o Brasil moderno, só se admitindo mão de obra menos qualificada para trabalhos mais simples, salientando-se a destinação industrial, para a qual interessa o estrangeiro que já possuía comprovada especialidade ou aptidão técnica, deixando para o elemento brasileiro local as atividades não especializadas ou incentivando as migrações internas dirigidas. ${ }^{3}$ Defendia-se, para isso, o núcleo familiar e, como dizia um articulista da revista, era necessária uma comparação das curvas de progresso do Brasil e dos EUA para se entenderem as diferenças não apenas de solo e clima, mas também de ordem moral e psicológica. Para Medeiros (1947), o europeu que fundou a "comunhão norteamericana" transportava-se para aquele país levando consigo o núcleo fundamental afetivo da agregação humana: a família.

O acordo para a recepção dos deslocados foi firmado com a United Nations Refugee Repatriation Association (UNRRA) em abril de 1947, selecionando, na medida do possível, grupos de agricultores, mas também de todas as profissões, cabendo a colocação ao Ministério do Trabalho e ao governo de São Paulo, estado pensado como destino preferencial desses imigrantes, conforme destaca Latour (1947). Segundo esse autor, as profissões mais procuradas eram: mecânico de todas as categorias e graus de especialização para montagem, reparação e conservação de motores e máquinas; operários e especialistas em fiação e tecelagem; especialistas em indústrias químicas; operários e especialistas em indústrias metalúrgicas; e operários de indústria de extração de carvão (LATOUR, 1947, p. 114).

\section{A imigração polonesa no contexto do pós-Segunda Guerra Mundial}

Assim, algumas características da imigração polonesa que serão apresentadas adiante encontram-se no contexto descrito para os deslocados, como a questão do caráter familiar da migração. Além disso, as correntes provenientes da Europa Centro-Oriental já se dirigiam ao Brasil desde as décadas finais do século XIX.

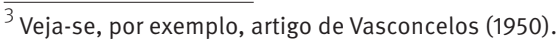


Em geral, tanto poloneses como ucranianos, húngaros e baltas foram afetados por uma emigração mais ou menos forçada, desde finais do século XIX, em função de vários fatores socioeconômicos e políticos que determinaram o retalhamento de suas terras, forçando milhares de pessoas a abandoná-las, principalmente nas províncias incorporadas ao Império Austro-Húngaro; uma segunda leva de emigrantes saiu por motivos políticos no final da Primeira Guerra e uma terceira no final da Segunda Guerra.

Por ocasião da visita da comissão brasileira aos campos de refugiados da Alemanha e da Áustria, havia cerca de um milhão de pessoas "deslocadas" que não desejavam voltar para as suas regiões de origem (PAIVA, 2000). ${ }^{4}$ Os poloneses formam o maior grupo dos "deslocados" que se dirigiram ao Brasil e, segundo Lobo (1950), destacavam-se por um nível profissional e educacional elevado, professavam religião católica e eram provenientes de regiões agrícolas da Polônia.

Os poloneses correspondiam a 30\% do contingente de deslocados reunidos nos campos de refugiados, seguidos pelos israelitas (20\%) e baltas 5 (17\%), onde também se encontravam ucranianos, ${ }^{6}$ russos, iugoslavos e apátridas. Viviam fora dos campos os Volksdeutsche, depois incorporados à proteção da OIR, ${ }^{7}$ de origem remota alemã que viviam há várias gerações em outros países como a Tchecoeslováquia e a lugoslávia e que, depois da guerra e em função de vários acordos, foram enviados à Alemanha e à Áustria, onde somavam 200.000 pessoas, com excelentes referências de trabalho profissional.

Apesar das diferentes experiências anteriores de cada um dos grupos, aqueles que já haviam vivido alguns anos nos campos de refugiados possuíam um elemento em comum: o treinamento profissional e alguma habilidade técnica, que os tornavam atraentes como possíveis candidatos à emigração e permitiriam, aos que pretendiam recompor suas famílias, que viessem acompanhados de esposas e filhos e, muitas vezes, de seus pais ou sogros ou outros parentes.

Decol (1999) estima o ingresso de mais de 200 mil poloneses no Brasil, nas sucessivas levas ingressantes em diferentes períodos. Em termos numéricos, o autor assinala que se trata de um fluxo correlato ao japonês (250 mil) e ao alemão (220 mil) e, em relação aos imigrantes provenientes do centro-leste europeu, o grupo polonês é o mais numeroso. Tampouco se pode desconsiderar o fato de que muitos foram classificados, nas estatísticas oficiais, como alemães, austríacos ou russos, ${ }^{8}$ dado que o território encontrava-se sob domínio

\footnotetext{
${ }^{4}$ Estima-se o deslocamento de 53.536.000 pessoas das suas cidades e países de origem, entre 1939 e 1947. Com o final da guerra, a maioria regressou às suas localidades originárias, todavia, cerca de um milhão de pessoas ali permanecera. Entre os fatores salientados para a não repatriação, Amaral (2005, p. 2) salienta "a total perda de conexão com seus países de origem, os quais haviam sido anexados por outros ou tiveram instalados, no pós-guerra, novos regimes políticos e sociais”.

${ }^{5}$ Segundo Lobo (1950), os baltas, provenientes da Letônia, Lituânia e Estônia, fugiram de seus países em 1944, primeiro em razão da invasão alemã e depois da russa, e acabaram realizando trabalhos forçados na Alemanha.

${ }^{6}$ Os ucranianos também possuíam excelentes referências de acordo com a comissão brasileira (LOBO, 1950).

${ }^{7}$ Organização Internacional das Migrações (OIR) ou International Refugees Organization (IRO).

${ }^{8}$ Decol (1999, p. 41) assinala que os poloneses provinham, sobretudo, das regiões ocupadas pela Rússia e, nesse sentido, foram estatisticamente classificados pelo governo brasileiro como russos.
} 
das potências imperialistas e não constam dessas estatísticas como poloneses. ${ }^{9}$ Decol aponta dois períodos de maior intensidade desse fluxo: o primeiro compreende os anos 1925 até as vésperas da Segunda Guerra Mundial; e o segundo corresponde ao pós-Segunda Guerra.

Em São Paulo, a imigração intensificou-se nos períodos anteriores e posteriores às duas guerras mundiais, ${ }^{10}$ caracterizando-se pela presença de pequenos comerciantes, profissionais liberais e operários em geral, que trabalhavam em oficinas, serrarias, etc. Os grupos que se diferenciavam na Polônia, segundo a religião, estavam também representados em São Paulo: católicos romanos, ortodoxos, protestantes e judeus. Na Polônia antes da guerra concentravase a maior população de origem judaica da Europa (DECOL, 1999), além de inúmeras etnias em convívio, independentemente da língua falada, costumes e religião.

\section{0 banco de dados e a imigração polonesa para o Brasil do pós-Segunda Guerra Mundial}

Desenvolvido entre 2003 e 2008 no âmbito do projeto "Novos imigrantes: fluxos migratórios e industrialização em São Paulo no pós-Segunda Guerra Mundial 1947-80”, o banco de dados que reúne os documentos analisados no presente artigo foi construído a partir da documentação ${ }^{11}$ então custodiada pelo Memorial do Imigrante/SP, com apoio da Fapesp, numa parceria institucional entre o Memorial e o Núcleo de Estudos de População (Nepo/Unicamp). A proposta então era analisar a dinâmica dos "novos" fluxos migratórios para São Paulo no período pós-Segunda Guerra Mundial, particularmente a inserção de trabalhadores considerados mão de obra qualificada oriundos da Europa e do Japão, em resposta ao crescimento da demanda por esse tipo de mão de obra para a indústria e a agricultura que se mecanizavam, especialmente no Estado e na cidade de São Paulo.

O banco de dados compreende as seguintes séries documentais: pedidos de mão de obra qualificada; avisos de chegada de imigrantes; ficha de registros de refugiados e deslocados de guerra; fichas de registros de imigrantes; curriculla vitae de imigrantes interessados em emigrar para o Brasil; fichas de colocação em empresas; e documentos pessoais. Os dados foram sistematizados em 45 campos, distribuídos em três tabelas: principal, acompanhante e profissão. ${ }^{12}$ Para o presente artigo, foram trabalhadas as informações referentes aos campos

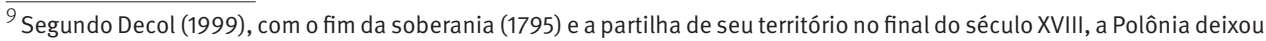
de constar do mapa político durante todo o século XIX, encontrando-se sob domínio da Prússia, do Império Russo e do Império Austro-Húngaro; esse fato acarreta a baixa incidência de dados sobre os imigrantes poloneses no Brasil no século XIX. Weber (2011) assinala a necessidade de se estabelecer um questionamento dos registros oficiais, visto que a questão conflitiva de seu território desde o século XVIII dificulta distingui-los dos lituanos, pomeranos, ucranianos, rutenos e eslavos.

${ }^{10}$ Decol (1999) aponta a estagnação econômica, a intolerância e a presença de partidos políticos de extrema direita como fatores decisivos para a emigração durante o período entre guerras.

${ }^{11}$ Em 2010/2011, o acervo documental do Memorial do Imigrante foi transferido para o Arquivo Público do Estado de São Paulo (Daesp).

${ }^{12}$ Os dados dos imigrantes foram sistematizados em três tabelas, organizadas a partir do imigrante principal. A primeira tabela sistematiza os dados do imigrante principal, a segunda reúne dados dos acompanhantes e a terceira concentra a experiência profissional do imigrante principal: dados sobre a formação escolar e empresas onde trabalhou, tanto no exterior quanto no Brasil.
} 
nacionalidade, naturalidade, origem, sexo, idade, estado civil, procedência, destino, posição familiar, profissão, empresa (contratadora), residência, data da chegada e observação.

Do ponto de vista cronológico, este conjunto documental divide-se em duas fases. A primeira corresponde ao período 1947-1951, englobando entradas majoritárias de refugiados de guerra, que, como se viu, constituem um grupo de imigrantes provenientes do centro e leste europeus e que entram basicamente pelos organismos internacionais, no caso, a Organização Internacional das Migrações (OIR) e Hebrew International Assistance (HIAS), encarregados do repatriamento e colocação em países europeus e não europeus.

A partir de 1952, após a extinção da OIR e criação do Comitê Intergovernamental para as Migrações Europeias (Cime), as entradas passaram a ser organizadas por este último e pelos acordos bilaterais entre os países, até o final dos anos 1970. Nesse período, modificase o perfil dos imigrantes, com entradas de diversas nacionalidades (italianos, espanhóis, alemães, suíços, japoneses, etc.), cuja característica básica é sua inserção urbana e industrial, sobretudo em São Paulo (SAKURAI; SALLES; PAIVA, 2008).

Do ponto de vista imigratório, o período do pós-Segunda Guerra Mundial caracteriza-se como a retomada da política imigratória, com o Decreto-Lei n. 7.967 de 18/09/1945, como visto anteriormente. Segundo o artigo n. 38 desse Decreto, a imigração dirigida ocorre quando o poder público, empresa ou particular promove a introdução de imigrantes, hospedandoos e localizando-os. E, no primeiro parágrafo, é apontada a preferência por famílias com pelo menos oito pessoas aptas para o trabalho, entre 15 e 50 anos (DIC, 1952, p. 121-124). Revogado esse Decreto com a Resolução do Conselho de Imigração e Colonização n. 1.676, de 18/10/1950, suprime-se o regime das cotas para imigrantes das nacionalidades portuguesa, espanhola, francesa e italiana. A partir de então, inúmeros acordos se firmaram entre o Brasil e os países europeus e o Japão.

O banco de dados reúne 18.369 registros de ingressos no período 1947 a 1951 , sendo os poloneses (26\%) o maior grupo entre 74 nacionalidades. Ressalta-se que 19\% dos registros encontram-se sem identificação da nacionalidade, o que resulta, provavelmente, de erro da digitação, omissão do documento ou ainda trata-se de imigrantes indocumentados, que preferiam que sua origem fosse ignorada. ${ }^{13}$ Os apátridas totalizam $11 \%$ dos ingressos e constituem o terceiro maior grupo, seguidos pelos ucranianos (9\%). Com 6\% destacamse os húngaros, iugoslavos e russos; com 3\% os de nacionalidades letã, italiana e lituana; com $2 \%$ os de nacionalidades checoslovena e romena e com $1 \%$ os alemães, holandeses, estonianos e armênios. Com menos de 1\% estão os de nacionalidades búlgara, austríaca, grega, portuguesa, espanhola, japonesa, brasileira, croata, colombiana, albanesa, turca, belga, chinesa, estadunidense, finlandesa, georgiana, libanesa, sueca e suíça.

\footnotetext{
$\overline{13}$ Em virtude do contexto em que se inscreve, postula-se a preservação de segurança individual. Durante o período 1931 a 1934, a Itália apresentou-se como um refúgio aos judeus, auxiliando-os para que se encaminhassem a uma nova pátria, quer na América ou na Palestina. Apesar dos sinais, apenas em 1938 foram aprovadas medidas de caráter antissemita, suprimiram-se os direitos dos judeus italianos e teve início a perseguição aos judeus italianos ou judeus estrangeiros. Este quadro agravou-se entre 1943 e 1945, com a política de extermínio desses judeus na Itália (CAMPAGNANO, 2011).
} 
Diferentemente dos imigrantes de períodos anteriores, os refugiados ingressaram pelo porto do Rio de Janeiro e foram acolhidos na Hospedaria da Itha das Flores. Uma vez identificado São Paulo como destino inicial, abrigaram-se provisoriamente na Hospedaria do Campo Limpo, localizada no município de Campo Limpo, visto que a Hospedaria de Imigrantes encontrava-se ocupada pela Escola de Aeronáutica (PAIVA, 2000).

No banco de dados completo constam 4.765 poloneses entrados no período de 1947 a 1978, sendo que para 17 pessoas o ano de ingresso é ainda anterior a 1947, o que pode indicar que se trata de uma solicitação de colocação profissional, ou seja, não se enquadram necessariamente na condição de “deslocados de guerra”. Entre 1947 e 1951, período selecionado para estudo, ingressaram 4.718 poloneses, dos quais 1.619 foram considerados imigrantes principais (71 mulheres e 1.548 homens) e 3.099 acompanhantes (2.132 mulheres e 967 homens).

Observa-se a presença de famílias, embora o número reduzido de acompanhantes não indique a família ampliada, visto que o banco reúne baixa incidência de primos(as) (2), sobrinhos(as) (7), sogros(as) (15), cunhados(as) (10), enteados(as) (35), irmãos(ãs) (47), netos(as) (6), noras (6), pais (14), mães (32), uma tia, um avô e uma madrasta. Nove esposas e quatro filhos constam da tabela principal como os responsáveis pelo registro, devendose destacar, neste sentido, o equilíbrio entre o número de chefes de família (1.235) e o de esposas (1.253), bem como o predomínio de filhos(as) (1.667) e, ainda, a existência de 405 pessoas que não esclarecerem sua posição de ingresso. Ressalta-se também a possibilidade de reunião familiar, com as nove esposas vindo encontrar os maridos já estabelecidos anteriormente no país. Assim, o caráter familiar é dado pela composição das famílias pelo chefe, esposa e filhos acompanhados de parentes e poucos agregados (5).

Nota-se que 320 pessoas (20\%) vieram desacompanhadas e, no que se refere à composição das famílias, prevalecem aquelas com três membros (458, ou 28\%), seguidas pelas compostas por duas pessoas (363, ou 22\%), ou seja, famílias pequenas. A análise da cidade de nascimento declarada pelo imigrante principal permite identificar 13 diferentes nacionalidades, com predomínio da polonesa (738, ou 46\%). Observa-se que o campo nacionalidade não foi preenchido de forma satisfatória, pois, apesar de se referir aos poloneses, a consolidação dos dados possibilita quantificar outras nacionalidades a partir do campo naturalidade: russa (28), alemã (18), ucraniana (16), romena (3), americana (3), italiana (2), húngara (2), lituana (2), polonesa ucraniana (2), iugoslava (2), checoslovena (1) e turca (1).

O campo destinado à formação escolar do imigrante não foi convenientemente preenchido. A formação de nível superior, em alguns casos, foi identificada a partir da análise da profissão declarada (3) ou do campo observação, o qual reuniu informações diversas, possibilitando identificar solicitação de visto de saída para outros países (principalmente, na década de 1950), ${ }^{14}$ dados sobre a profissão registrada no passaporte, reclassificação

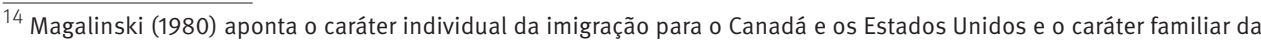
imigração para o Brasil.
} 
da profissão, núpcias, óbitos, dados sobre contratação profissional (empresa, endereço, remuneração e modalidade da atividade desempenhada), etc.

Para o grupo analisado, que teve entrada de 1947 a 1951, verifica-se no campo "observação" da base de dados que a solicitação de visto de saída teve início em 1951 (5), sendo que os anos de maior incidência foram 1958 (208) e 1957 (131). ${ }^{15}$ Cerca de 9\% dos poloneses (448) que entraram no período requereram visto, dos quais a maioria foi para os Estados Unidos (333) e outros dirigiram-se para o Canadá (55), Polônia (17), Argentina (14), Austrália (12), Alemanha (10), Uruguai (5) e Áustria (1). Registre-se que esse campo contempla a solicitação de visto de saída, mas poucos são os casos em que sua concretização é indicada (33), ou se a saída é definitiva (5). No campo observação de uma mulher, constam, em 1957, solicitações de visto para Holanda, Suiç̧a, Itália e França e, no ano seguinte, para a Alemanha, mas não se sabe qual desses visto foi concedido.

A sistematização do campo profissão permite compreender a natureza da mão de obra desses imigrantes. Notam-se, na Tabela 1, predomínio de trabalhadores da produção e bens de serviços industriais (45\%) e pequeno número de técnicos de nível médio (11\%) e de trabalhadores de reparação e manutenção (9\%). Vale destacar que, na área de produção e bens de serviços industriais, havia grande incidência de trabalhadores das indústrias têxtil e do vestuário (45\%), da transformação de metais (24\%) e da construção civil (20\%).

TABELA 1

Distribuição dos imigrantes poloneses que entraram no Brasil entre 1947 e 1951, segundo ocupações

\begin{tabular}{lrr}
\hline \multicolumn{1}{c}{ Ocupações (1) } & N. abs. & \% \\
\hline Dirigentes de organizações de interesse público e de empresas, gerentes & 1 & 0,0 \\
Profissionais das ciências e das artes & 39 & 2,0 \\
Técnicos de nível médio & 278 & 11,0 \\
Trabalhadores de serviços administrativos & 73 & 3,0 \\
Trabalhadores dos serviços, vendedores do comércio em lojas e mercados & 129 & 5,0 \\
Trabalhadores agropecuários, florestais e da pesca & 120 & 5,0 \\
Trabalhadores da produção e bens de serviços industriais & 1.126 & 45,0 \\
Trabalhadores de reparação e manutenção & 217 & 9,0 \\
Outros & 492 & 20,0 \\
Total & $\mathbf{2 . 4 7 5}$ & $\mathbf{1 0 0 , 0}$ \\
\hline
\end{tabular}

Fonte: Projeto Novos imigrantes: fluxos migratórios e industrialização em São Paulo no Pós-Segunda Guerra Mundial $1947-80$.

(1) De acordo com a Classificação Brasileira de Ocupações - CBO (2002).

Naquela época, o país demandava a vinda de agricultores e técnicos qualificados. Nesse sentido, no que se refere à mão de obra especializada, nota-se o predomínio de técnicos relacionados às áreas de engenharia, física, química e campos afins, bem como alguns profissionais com nível superior, quesito problematizado a seguir.

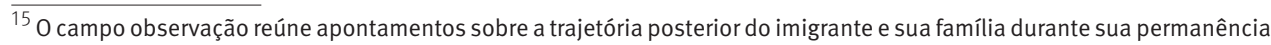
no Brasil.
} 
Registre-se que 11 engenheiros não foram admitidos no país com essa qualificação, tendo sido classificados como assistente técnico (2), calculista (1), desenhista (2), industriário (1), serralheiro (1), técnico eletricista (1), técnico em arquitetura (1) e topógrafo (1). O físico foi classificado como auxiliar desenhista (1), enquanto apenas dois engenheiros (hidrotécnico e mecânico) foram admitidos com suas respectivas especialidades e classificados como profissionais das ciências exatas, físicas e da engenharia, juntamente com um engenheiro (acompanhante), três químicos e três agrimensores.

Nota-se que também ingressaram profissionais da área da saúde, destacando-se quatro enfermeiras, um assistente de médico, um técnico em ginecologia, um dentista e um zootécnico. Como comunicadores, artistas e religiosos, computam-se três músicos e, com único registro cada, jornalista, pintor artístico, decorador, cenógrafo, padre, pastor batista e pároco. Sem detalhamento de atuação constam cinco professores classificados como profissionais de ensino. 0 único pesquisador existente é um entomologista, enquanto o técnico economista foi classificado como profissional das ciências sociais e humanas.

Como já destacado, no campo observação, também foi anotada a reclassificação da profissão do imigrante. Nesse sentido, mantém-se a coerência do registro da profissão relativa à profissão transcrita do passaporte e profissão registrada. Observa-se que o físico foi admitido como técnico em física e apenas dois engenheiros ingressaram e atuaram como engenheiros, enquanto os demais foram admitidos como desenhista (1), desenhista construtor (1), industriário e técnicos: construtor (1), eletricista (2), mecânico (2), mecânico e montador (1), topógrafo e hidrotécnico (1) e um não consta nenhuma informação.

Como trabalhadores de serviços administrativos, encontravam-se 71 escriturários e cinco atendentes ao público. Havia, ainda, 56 trabalhadores dos serviços e 74 vendedores do comércio em lojas e mercados.

As atividades agropecuárias, florestais e da pesca agregavam 110 trabalhadores na exploração agropecuária, oito na mecanização agropecuária e florestal e um na pecuária. Ao se cotejar a orientação designada pela empresa contratadora, confirma-se sua concentração no Estado de São Paulo, principal centro contratador dos trabalhadores que se declararam agricultores (79\%), embora seja desconhecida a localidade de 15\% desses contratadores. Considerando-se os municípios de destino de acordo com a atual configuração das regiões administrativas paulistas, observa-se predomínio de fixação dos poloneses na Região Metropolitana de São Paulo (16\%), Região Administrativa de Bauru (12\%), Região Administrativa de Marília (3\%), Região Administrativa de Campinas (2\%) e uma única ocorrência na Região Administrativa de São José do Rio Preto. Sabe-se que sete imigrantes dirigiram-se para Goiás (Jussara), sete para Minas Gerais (Cascalho), um para Santa Catarina (Curitibanos) e um para Tocantins (Araguaçu). A esse conjunto acrescentam-se 61 parentes que também declararam esse ofício, mas não constam informações sobre os contratadores.

Observam-se outras ocupações declaradas pelos agricultores, tais como carpinteiro, eletricista, encanador, industriário, litógrafo, mecânico, salsicheiro, sapateiro e pedreiro. Tal elemento também é mencionado por Magalinski (1980), que destaca os ofícios aprendidos 
nos campos de refugiados na Europa. O autor aponta, ainda, o estímulo nessa modalidade de declaração, visto que o Brasil requeria agricultores e técnicos e, na ausência da especialização exigida, muitos afirmavam ser agricultores.

No que se refere ao município de São Paulo, a maioria das famílias identificadas (449) fixou-se, inicialmente, nas Zonas Leste (138), Oeste (112) e Norte (88). Na área central (28) poucas foram as que se instalaram no Bairro do Bom Retiro (7), onde se concentrava a maioria dos poloneses já residentes, dirigindo-se para novas regiões, próximas aos setores industriais, como Vila Prudente (100), no sentido leste, e Lapa (99), no oeste. Justamente no setor oeste constituíra-se o Centro Industrial do Jaguaré, ${ }^{16}$ bairro industrial planejado por Henrique Dumont Villares, em terrenos adquiridos pela Sociedade Imobiliária Jaguaré em 1935. Os trabalhadores adivinham dos bairros operários da Lapa, Pinheiros e Presidente Altino e a produção era facilmente escoada pelas marginais (PISANI, 2011).

Na Região Metropolitana de São Paulo, os municípios de São Caetano do Sul (186) e Santo André (30), vizinhos dos bairros da Zona Leste paulistana, também receberam expressivos contingentes. Em direção oposta, no oeste, Osasco (37) e Presidente Altino (32) revelaramse destinos prioritários.

Nesse período, um dos fatos mais significativos foi o desenvolvimento industrial de Osasco, nas proximidades da Lapa e de Presidente Altino, bem como a intensificação do parque industrial de São Caetano e Santo André. Na direção oposta, nas proximidades da Lapa, como já destacado, também se estabelecia uma nova região industrial: O Centro Industrial do Jaguaré.

Do conjunto de mais de 600 empresas identificadas, os maiores contratadores foram: Indústrias Reunidas Francisco Matarazzo S/A (58); Frigorífico Armourdo Brasil S/A (40); Frigorífico Wilson do Brasil S/A (37); The São Paulo Tramway Light and Power Company Ltda. (29); Nestlé (24); Companhia Vidraria Santa Marina (23); e Max Lowenstein \& Cia. (20).

\section{Destino}

O acordo assinado entre a União e o do Estado de São Paulo, aprovado pelo DecretoLei n. 9.534, de 31 de julho de 1946, previa a introdução de imigrantes europeus a serem dirigidos aos trabalhos agrícolas e industriais. Esse acordo permitia a seleção profissional, composição de famílias, nacionalidades, portos de origem e outras condições asseguradas conforme os interesses do Estado.

Os deslocados começaram a chegar ao Brasil a partir de maio de 1947. Os primeiros contingentes foram encaminhados para a agricultura ou para a indústria. As reclamações não tardaram a acontecer da parte dos que receberam as primeiras levas na lavoura. As atividades eram desempenhadas nas fazendas de café, nas grandes propriedades não cafeeiras, em pequenos sítios de colonos prósperos e em chácaras ou granjas em geral próximas de São

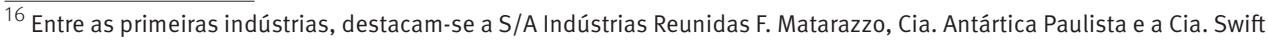
do Brasil (PISANI, 2011).
} 
Paulo ou de outros centros urbanos. A inadaptação e as reclamações mais comuns deviam-se aos seguintes fatos: imigrantes classificados como trabalhadores agrícolas ou agricultores que não eram dessa profissão; trabalhadores que não se adaptavam às condições locais de trabalho; descontentamento com o salário que não lhes permitia o nível de vida a que estavam habituados antes da guerra; mulheres dos agricultores que haviam se casado na Alemanha e que não tinham vivido no meio rural e concorriam para o desajuste; famílias pouco numerosas para o trabalho, ou seja, menos de três pessoas aptas para o trabalho; falta de informações e preparação para as condições da vida rural; insatisfação por não poderem se transformar em pequenos proprietários rurais (VASCONCELOS, 1950).

Para minimizar as reclamações, segundo Vasconcelos (1950), iniciou-se, ainda na Hospedaria de Campo Limpo, uma pesquisa mais detalhada sobre as ocupações antes, durante e após a guerra. Embora houvesse uma ficha de classificação profissional nos campos de refugiados na Alemanha e na Áustria, existiam muitos erros, sendo que o principal era classificar a maioria dos imigrantes como agricultores. Por outro lado, a maior adaptação ocorreu nos casos de famílias numerosas, hábitos de trabalho agrícola anteriores e casais constituídos antes da guerra. Pode-se então inferir que as correções contidas no item Observação, analisado nesse artigo, podem se dever a esse fato.

Desde 1945, quando retomou-se a imigração, até 1954, quando foi criado o Instituto Nacional de Imigração e Colonização (Inic), dos imigrantes que entraram no Brasil, havia 11.216 agricultores, 67.319 operários em geral, 6.280 qualificados, 4.535 técnicos, 134.806 domésticos, além de 89.402 não especificados (PEQUENO, 1957).

Esses dados, obtidos graças à boa vontade de técnicos do Instituto, revelam que não estão sendo atendidas as exigências da produção nacional relativamente à mão de obra qualificada. Necessitamos de muito mais para atender ao surto industrial do Brasil, apesar do substancial auxílio do SENAI (PEQUENO, 1957, p. 10).

De certa forma, esses dados reafirmam o caráter diferenciado da imigração pós-guerra, que o presente artigo procurou mostrar, em relação ao período da grande imigração, e caracterizado sobretudo por profissões voltadas para suprir a necessidade de operários e técnicos, apesar de ainda se verificar a entrada de número significativo de agricultores, como se procurou justificar.

\section{Considerações finais}

Objetivou-se, neste artigo, traçar um perfil dos imigrantes de nacionalidade polonesa no Estado de São Paulo no contexto mais geral da imigração do pós-Segunda Guerra Mundial, em que os poloneses entraram juntamente com as demais nacionalidades dos chamados “deslocados de guerra”, no período 1947-51, quando as entradas foram patrocinadas, em sua maioria, pela Organização Internacional dos Refugiados. Observaram-se, para tanto, a retomada da imigração pelo Brasil, em 1945, e a legislação imigratória que, apesar da preferência por imigrantes de origem latina como portugueses, espanhóis e italianos, discutiu e aprovou a entrada 
de imigrantes provenientes dos campos de refugiados da Alemanha e da Áustria, em parte por razões humanitárias que eram propaladas, mas sobretudo pelo caráter técnico e especializado desses imigrantes que possuíam qualificação muitas vezes obtida nos próprios campos.

Espera-se que o artigo tenha evidenciado as especificidades dos “deslocados de guerra“ em relação aos imigrantes chamados de latinos, que eram considerados preferenciais, e que tenha chamado a atenção para a necessidade de estudos comparativos sobre as principais nacionalidades dos imigrantes que entraram no país no pós-guerra. Nesse caso, os grupos dos chamados latinos, presentes significativamente no banco de dados e que merecem aprofundamento, são os italianos e espanhóis, que também ingressaram em grande número por meio de redes anteriormente constituídas. Além desses grupos, evidentemente os japoneses também merecem estudo aprofundado.

Por outro lado, a presença de famílias entre os imigrantes entrados pela Hospedaria, objeto do banco de dados aqui analisado, reforça os motivos da vinda e da escolha do Brasil, em detrimento de países como o Canadá, por exemplo, que privilegiavam imigrantes individuais. Nesse caso, observam-se a prevalência da política imigratória brasileira voltada para a imigração familiar e a permanência da solicitação de agricultores, além dos profissionais apontados.

Verificou-se, também, que a entrada de grande número de imigrantes classificados como trabalhadores da produção de bens e serviços industriais (cerca de 45\%) e técnicos respondia à solicitação por profissionais para a indústria e para a agricultura que se modernizava. Esses dados apontam a necessidade de uma comparação com outras nacionalidades presentes no banco de dados aqui apresentado. De qualquer maneira, parece que as profissões registradas no passaporte não correspondiam aos empregos efetivamente conseguidos e desempenhados nos primeiros tempos, tendo sido observada uma reclassificação de engenheiros para técnicos e outras reclassificações.

O perfil apresentado ainda mostra o ingresso pelo Porto do Rio de Janeiro, com uma permanência curta na Hospedaria da Iha das Flores até a definição das empresas contratadoras, concentradas principalmente na Região Metropolitana de São Paulo, com destaque para a capital paulista.

Fundamentados no discurso da carência de mão obra especializada e de braços para a agricultura, os representantes do Estado brasileiro na Europa demandaram trabalhadores para a lavoura e para o parque industrial que se modernizava e estimularam o ingresso de famílias, para o que contavam com o apoio da IRO. Entretanto, é possível afirmar que há uma concentração de empresas contratadoras no Estado de São Paulo, com predominância da Região Metropolitana de São Paulo e de algumas regiões administrativas, como as de Bauru, Marília e Campinas. Importante observar que, na Região Metropolitana de São Paulo, os imigrantes poloneses concentraram-se em São Caetano, Santo André, municípios em processo de industrialização, e em Osasco.

Finalmente, espera-se, com este artigo, indicar a necessidade de, no quadro da modernização, abertura e industrialização que caracterizaram o período do pós-Segunda 
Guerra Mundial, serem inseridas análises que ressaltem o papel da imigração proveniente do Leste da Europa e, posteriormente, de países tradicionalmente fornecedores de imigrantes ao Brasil, dirigidos agora às cidades e à indústria preferencialmente, ao lado das análises sobre mão de obra proveniente da migração interna, de papel indiscutível na industrialização paulista.

\section{Referências}

ANDRADE, J. H. F. O Brasil e a organização internacional para os refugiados (1946-1952). Rev. Bras. Polít. Int., v. 48, n. 1, p. 60-96, 2005.

BAENINGER, R. Fases e faces da migração em São Paulo. Campinas: Nepo/Unicamp, 2012.

BASSANEZI, M. S. B. Imigrações internacionais no Brasil: um panorama histórico. In: PATARRA, N. (Coord.). Emigração e imigração internacionais no Brasil contemporâneo. $2^{a}$ ed. São Paulo, FNUAP, v. 1, 1995.

BRASIL. Lei 7.967, de 18 de setembro de 1945. Dispõe sôbre a Imigração e Colonização, e dá outras providências.

CAMPAGNANO, A. R. In difesa della razza. Os judeus italianos refugiados do fascismo e o antissemitismo do Governo Vargas, 1938-1945. São Paulo: Edusp/Fapesp, 2011.

CENNI, F. Italianos no Brasil. "Andiamo in Mérica”. São Paulo: Edusp, 2002.

DECOL, R. D. Imigrações urbanas para o Brasil: o caso dos judeus. Tese (Doutorado em Sociologia). Campinas: Universidade Estadual de Campinas - Unicamp, 1999.

DIC. Legislação Imigratória. Boletim do Departamento de Imigração e Colonização, Secretaria da Agricultura do Estado de São Paulo, n. 7, dez. 1952.

FAUSTO, B. Historiografia da imigração para São Paulo. São Paulo: Idesp/Editora Sumaré, 1991.

KOIFMAN, F. Imigrante ideal. O Ministério da Justiça e a entrada de estrangeiros no Brasil (1941-1945). Rio de Janeiro: Civilização Brasileira, 2012.

LATOUR, J. Displaced persons. Revista de Imigração e Colonização, n. 4, dez. de 1947.

LEVY, M. S. F. O papel da migração internacional na evolução da população brasileira (1872 a 1972). Revista de Saúde Pública, v. 8 (Supl.), p. 49-90, 1974.

LOBO, H. Seleção dos deslocados. Boletim do Departamento de Imigração e Colonização, n. 5, dez. 1950 .

MAGALINSKI, J. Deslocados de guerra em Goiás. Imigrantes poloneses em Itaberaí. Goiania: UFG, 1980. MEDEIROS, M. O problema da imigração. Revista Imigração e Colonização, n. 1, mar. 1947.

MONTEIRO, R.; BASTOS, S. R. Imigração coreana: a questão da reimigração e do retorno. Revista Travessia, ano XXIV, n. 69, p. 47-55, jul.-dez. 2011.

PAIVA, O. Refugiados de guerra e imigração para o Brasil nos anos 1940 e 1950. Apontamentos. Revista Travessia, ano XIII, n. 37, p. 25-30, maio-ago. 2000.

PEQUENO, M. D. Imigração e mão de obra qualificada. Rio de Janeiro: Serviço de Documentação do MTIC, 1957.

PERES, E. P. Proverbial hospitalidade? A Revista de Imigração e Colonização e o discurso oficial sobre o imigrante (1945-1955). Acervo. Revista do Arquivo Nacional, v. 10, n. 2, p. 53-70, jul.-dez. 1997.

PISANI, M. A. J. Indústria e favela no Jaguaré: o palimpsesto das políticas públicas de habitação social. Vitruvius, ano 11, abr. 2011. 
POSWAR. Projeto Novos imigrantes: fluxos migratórios e industrialização em São Paulo no Pós Segunda Guerra Mundial 1947-80. Fapesp, 2003 a 2006.

SAKURAI, C.; SALLES, M. R. R.; PAIVA, O. Guia do banco de dados. Relatório científico. São Paulo: Fapesp, 2008.

TRENTO, A. Do outro lado do Atlântico: um século de imigração italiana no Brasil. São Paulo: Nobel, 1989.

VASCONCELOS, H. D. O problema da imigração no pós guerra. Boletim do Departamento de Imigração e Colonização, Secretaria de Agricultura do Estado de São Paulo, n. 5, dezembro, 1950.

WEBER, R. Historiografia da imigração polonesa: entre números e identidades. In: XXVI SIMPÓSIO NACIONAL DE HISTÓRIA - ANPUH. Anais... São Paulo: ANPUH, 2011. p. 1-12.

\section{Autoras}

Sênia Bastos é doutora em História (PUC-SP) e professora da Universidade Anhembi Morumbi.

Maria do Rosário Rolfsen Salles é doutora em Ciências Sociais (Unesp, Araraquara). Docente e pesquisadora junto ao Mestrado em Hospitalidade da Universidade Anhembi Morumbi, São Paulo.

\section{Endereço de correspondência}

Maria do Rosário Rolfsen Salles

Rua Casa do Ator, $294-7^{\circ}$ andar, Vila Olímpia

São Paulo, SP - CEP 04546-000

\section{Abstract}

Polish immigration to São Paulo after World War II in the context of the immigrations of displaced persons: 1947-1951

This paper deals with the social history of the immigration to São Paulo. It focuses specifically on the period that is usually known as the resumption of immigration after World War II, when the arrivals of immigrants were divided basically into two periods: 1947-1951, with backing from the International Organization for Migration (IOM), and from 1952 to 1980, with the support of the Intergovernmental Committee for European Migration (ICEM). This paper focuses on the so-called "displaced persons" of Polish nationality, one among many groups of different nationalities who were freed from the refugee camps in Germany and Austria. This study was supported by documentation from the Immigrant Memorial, which has been systemized into a database, and is based on articles published in the Journal of Immigration and Colonization (JIC). The aim of this study is to contextualize the discussion on the need and convenience of the arrival of these displaced Polish immigrants, who were taken in through agreements between Brazil and the IRO at that time. This paper also outlines the profile of these immigrants, characterized as the largest group among the nationalities that arrived in Brazil during that period. The focus on post-war Polish immigration indicates the specific character of this group, whose profile differed from previous waves of immigrants to Brazil in a context strongly marked by movements to protect Brazilian workers and internal migrants.

Keywords: Immigration. Post-war. Displaced persons. Poles. São Paulo. 


\section{Resumen}

La inmigración polonesa hacia São Paulo en la Pos Segunda Guerra Mundial en el marco de los ingresos de los desplazados de guerra: 1947 a 1951

El presente artículo se inserta en el ámbito de la historia social de la inmigración hacia São Paulo, enfocando específicamente el periodo que se suele clasificar como la retomada de la inmigración, en la pos Segunda Guerra Mundial, cuando las entradas se dividen básicamente en dos periodos: 1947-1951, con el apoyo de la Organización Internacional de las Migraciones (OIR) y 1952-1980, con el apoyo del Comité Intergubernamental para las Migraciones Europeas (CIME). Enfoca la nacionalidad polonesa en el marco de la inmigración de los chamados "desplazados de guerra", constituidos por personas provenientes de distintas ciudades en los campos de refugiados de Alemania y Austria. Apoyado en la documentación del Memorial del Inmigrante, sistematizada en un banco de datos, y en los artículos publicados en la Revista de Imigração e Colonização (RIC), tiene el objetivo de contextualizar la discusión del periodo, sobre la necesidad y la conveniencia del ingreso de dichos inmigrantes desplazados que fueron introducidos gracias a acuerdos entre Brasil y la OIR, además de trazar el perfil de estos inmigrantes, que se caracterizaban como el mayor grupo entre las nacionalidades que ingresaron en el mencionado periodo. El enfoque en la inmigración polonesa de la posguerra destaca la especificidad de este flujo, cuyo perfil se diferencia de los flujos anteriores en un contexto marcado preferentemente por la protección al trabajador nacional y al migrante interno.

Palabras-claves: Inmigración. Posguerra. Desplazados. Poloneses. São Paulo.

Recebido para publicação em 29/11/2012

Aceito para publicação em 27/04/2014 
